\title{
Science has a solution for sonic weapons caused cancer
}

\author{
Robert Skopec* \\ Analyst-researchers, Dubnik, Slovakia
}

\begin{abstract}
U.S. personell at the Embassy in Havana who've experienced a rash of symptoms from mysterious sonic health attacks appear to have suffered widespread brain network dysfunction, but there's no answer about the cause. A new peer-reviewed medical report published by the Journal of the American Medical Association, is the first of its kind on the question that has vexed U.S. officials for over a year now, with 24 Americans suffering from medically confirmed symptoms, according to the U.S. State Department, and what new report's authors call neurotrauma from a nonnatural source.
\end{abstract}

\section{Introduction}

The State Department gave doctors at the University of Pennsylvania's Perelman school of Medicine access to 21 individuals. Of the 21, 18 reported hearing a noise - novel, localized sound at the onset of symptoms in their homes and hotel rooms. They described it as directional, intensely loud, and with pure and sustained tonality. Twelve of the 18 said it was associated with a pressure-like or vibratory sensation, and two of the three who didn't hear a sound also experienced that. All 20 those experienced an immediate onset of neurological symptoms after experiencing phenomena, and the one other individual awoke with immediate symptoms, but experienced no phenomena.

But what seems key is that first term - directional - a distinct direction from which the sensation emanated. In fact, 12 said that after changing location, the sensation disappeared, and the associated symptoms reduced. The most commonly-reported symptoms, in order, were persistent trouble sleeping, visual problems like eye movement abnormalities, cognitive difficulty like memory loss, inability to concentrate, headaches, balance problems, and auditory symptoms like tinnitus and hearing loss.

Some individuals developed symptoms within 24 hours of arriving in Havana, according to the report, and virtually all of them reported persistent symptoms lasting more than three months - with 18 exhibiting objective clinical manifestations when they were examined. On average, examinations took place 203 days after exposure, because the State Department didn't convene an expert medical panel until July 2017.

Three individuals suffered hearing loss and were fitted with hearing aids, but for two of them only on one side. In fact, having unilateral symptoms - where only one side is affected - was common in a couple cases, the report said. While the symptoms are that of widespread brain network dysfunctions as seen in mild traumatic brain injury, or concussion, they found no proof damage to the brain's white matter. MRIs on all 21 were largely normal. The individuals have seen improvements with therapy - 13 of them were referred for cognitive rehabilitation, 17 for rehab to improve balance, and 14 for rehab to improve eye function. But of the 14 held from work at the time of evaluation, seven did not return to limited work even after beginning therapy. The authors admit the study is not perfect. (The Washington Post, 2018).

\section{Material and methods}

The problematic ultrasound causes some U.S. officials have speculated that the attacks could have been conducted by rogue elements within Cuban government or military, or by agents of an unidentified third country. The JAMA article said that affected diplomats described the sound as directional, intensely loud, and with pure and sustained tonality. The conclusion of the JAMA article is absolutely unacceptable, when they are raising the issue of possible "collective delusional disorders". Several if the objective manifestations consistently found in this cohort including vision and balance abnormalities could not have been consciously or unconsciously manipulated! (Skopec III., 2017).

Professor Kevin Fu and members of the Security and Privacy Research Group at the University of Michigan say they have an explanation for what could have happened in U. S. Embassy in Havana: two sources of ultrasound - such as listening devices - placed too close together could generate interference and provoke the intense sounds similar to those of Havana victims. My point is that symptoms like hearing loss, headaches, cognitive problems and balance problems can't be strictly connected to the coincidently occurring so many times of placed too close ultrasound generators in office, at home and other different places. It is absolutely impossible and with zero probability!

It is valid by my opinion for all theories based on the ultrasound.

Many experts and American politicians have pointed microwave caused brain damage and to Russia as possible culprits for attacks. This would imply that the Cuban government must have known whether foreign actors were involved. Other theories have suggested that a faction within the Cuban government could have acted on its own, but this many observers believe is unlikely.

${ }^{\star}$ Correspondence to: Robert Skopec, analyst-researchers, Dubnik, Slovakia, E-mail: zxcbnvm7@gmail.com

Key words: Neurotrauma, nonnatural sources, sonic health attacks, brain network dysfunction, JAMA, State Department, hearing loss, tinnitus, balance problems, headaches, auditory symptoms

Received: February 26, 2018; Accepted: March 13, 2018; Published: March 15 2018 
The Michigan report also notes the lack of consensus and scientific research on damage caused by ultrasound. (Fu \& Xu, 2018).

Infrasound as the cause of the diplomat's damages Sound can also affect the physical world, as when a singer shatters a wine glass. Microelectrical mechanical sensing chips - such as accelometers used in car airbag systems and smartphones, and gyroscopes in drones are susceptible to the same interference. Those systems can be attacked with sound, crashing a drone mid-flight, or fooling a smartphone about whether it's moving.

It's well-kown that sounds that are too loud can damage people's ears and hearing. There is little evidence of ultrasound causing bodily harm without prolonged, direct physical contact at high intensity. To this cause is more acceptable the infrasound. If you are accidentally subjected to extremely intense ultrasound (such as when holding an ultrasonic arc welder), you could experience an annoyance like a headache or temporary loss of balance. Researchers disagree about safe levels of airborne ultrasound. The U.S. Occupational Safety and Health Administration warns of potential health risks from audible byproducts of ultrasound, more than the ultrasound itself.

Many animals can hear higher frequencies than humans. Dogs can hear higher-pitched whistles. Pet turtles would begin to dance rhythmically when they were taking part in ultrasound experiments.

The one of true cause, but not all, could have been also the equipment trying to listen in on diplomats' and visitor's conversations.

\section{Bad vibrations: investigating sound as terror}

Steve Goodman is a critic as he said of toxic world where a radioactive event has laid the land to waste. Sound has a very special power of creating irritation and bad vibes. As a scholar, Goodman studies for the sound repel or harm listeners. At one of his exhibition he was introduced his concept of Audio Intelligence (AUDiNT), in what he was referred at various military uses of sound.

In 2009, MIT Press published his book titled Sonic Warfare. We look at everything, in the book, from the military using acoustic weaponry to the way sound is used in branding and advertising, to the way intense sound is used by various music cultures around the world to build collectivity, Goodman explains. His work with AUDiNT looks at the way sound has been used to aid destruction. The group takes the detailed historical research of his scholarly work.

What we're doing is tracing or mapping these three phases of the history of acoustic weaponry, Goodman says. Firstly, starting with the Second World war, there was a division of the U.S. Army that was referred to as the Ghost Army. Part of what they were involved in was sonic deception, putting loud speakers in the battlefield to create a false impression.

So we trace this from the Second World War to the U.S. Army in Vietnam, a division of psychological operations called Wandering Soul. This involved helicopter-mounted loudspeakers playing simulated Buddhist chants, fabricated sounds of the dead ancestors of the Viet Cong fighters speaking to them from "the afterlife" to try and persuade them to surrender.

The third phase is less psychological, looking at a sound's potential to be a more conventional weapon.

What's starting to emerge now, Goodman says, is the use of these ultrasound driven directional audio speakers. These speakers can actually rupture eardrum from distance. Despite such advances in sonic technology, the old psychological tactics are still being used. Toby Heys, a fellow researcher at AUDiNT, says the U.S. military's use of sound with prisoners at Guantanamo Bay has been well-documented.

A lot of the detainees who were interviewed after their detainment have spoken about sonic torture as being the worst, Heys says. Rather than the sexual humiliation, rather than the beatings, the worst thing that they went trough was the sonic torture.

Nina Kraus, a neurobiologist at Northwestern University who studies the human auditory system, explains how sound triggers responses like fear in the human brain. We know that our auditory system has direct connections to our limbic system, which modulates emotions such as fear that will strengthen these neural circuits, Kraus says. She adds that those connections are unique to each individual, so no two people will hear a sound in exactly the same way.

Because of the experience that a person has had throughout their lives using sound, now when any sound occurs and, in this case, emotionally salient sounds then the nervous system will respond in a way that will particularly enhance the information bearing elements of the sound.

For a child raised in an urban environment, the sound of an ice cream truck might trigger desire of sweets, while those who have never been around a vendor on wheels may find the looping melodies an annoyance. Heys says that the U.S. troops have employed an exaggerated version of this idea in Afganistan. Before they embark they cleanse the area, but it's like this cultural cleansing, Heys says. They're playing heavy metal music, they're playing rap music, etc. Depending on your cultural experiences, the booming bass lines of Kode9's music may sound either threatening or inviting.

There is a political dimension to sound that people often ignore, and this called Goodman in his first book the politics of frequency. The way certain frequencies change the way you feel the way they resonate with different parts of the body, tapping into physiological and psychological dimensions of your experience. There is a need to open up the othet dimension, to get people thinking about sonic culture.

People often celebrate the healing power of music, it can distract us and put us at ease. But Goodman's work demonstrates that sonic culture can be something more than just a pleasantry, and that it's worth trying to understand the full scope of its power, even if it hurts. (AUDiNT, 2014).

\section{Results}

Exposure to infrasound has been demonstrated to affects recipients with symptoms including fear, sorrow, depression, anxiety, nausea, chest pressure and hallucination. It can cause objects to move through vibration and the body's internal organs can be affected.

The term infrasonic applied to sound refers to sound waves below the frequencies of audible sound. Nominally includes frequencies under $20 \mathrm{~Hz}$. Sources of infrasound in nature includes volcanoes, avalanches, earthquakes and meteorites.

The healthy human ear can hear frequencies ranging from $20 \mathrm{~Hz}$ to $20,000 \mathrm{~Hz}$. Over time, the hair-like stereocilia may get damaged or broken. If enough of them are damaged, hearing loss results. The high frequency area of the cochlea is often damaged by loud sound.

Infrasound is sound which extends below the range of human hearing (from $20 \mathrm{~Hz}$ to $0.001 \mathrm{~Hz}$ ), and it emitates from many natural and man-made sources. For example, some animals, such as whales, 
elephants and giraffes communicate using infrasound over long distances.

Sonic and ultrasonic weapons (USW) are weapons of various types that use sound to injure, incapacitate, or kill a target. New personal communications shows that infrasound can cause trough vibrations, resonance frequency about $7 \mathrm{~Hz}$ with internal organs of humans cause also cancer, such as colorectal cancer, pancreatic cancer, etc. (Skopec II., 2017).

Some of these weapons have been described as sonic bullets, sonic grenades, sonic mines, or sonic cannons. Some USWs make a focused beam of sound or ultrasound, some made an area field of sound.

As an example of used sonic weapon we can use The LRAD Sound Cannon as an acoustic weapon and communication device. Developed by the LRAD Corporation to broadcast messages and pain-inducing deterrent tones over long distances. LRAD devices come in various iterations that produce varying degrees of sound. They can be mounted to a vehicle or handheld. (Baldwin, 2014).

Protests in Fergusson, Missouri have reached a terrifying fever pitch, and the ludicrously armed Fersguson Police Department is bringing all its crowd-control weapons to bear, tear gas, stun grenades, rubber bullets. One of the most controversial of those is the LRAD Sound Cannon. The device produces a sound that can be directed in a beam up to 30-degress wide, and the military-grade LRAD 2000X can transmit voice commands at up to $162 \mathrm{~dB}$ up to 5.5 miles away.

The LRAD Corporation says that anyone within a 100 meters of the device's sound path will experience an extreme pain. The version generally utilized by Police Departments (the LRAD 500X) is designed to communicate at up to 2000 meters during ideal conditions. In a typical outdoor environment, the device can be heard for 650 meters. The 500X is also capable of short bursts of directed sound that cause headaches in anyone within a 300-meter range. Anyone within 15 meters of the device's audio path can experience permanent hearing loss. LRAD claims the device is not a weapon, but a directed-sound communication device (Figure 1).

\section{Conclusions}

The LRAD device has been used on several occasions against activists in the USA. The first documented use was in Pittsburgh during the G20 Summit in 2009. The Pittsburgh police used it again following the Superbowl in 2011. The LRAD has been reportedly used against Occupy protestors in Oakland and against Occupy Wall Street protestors in Zuccotti Park.

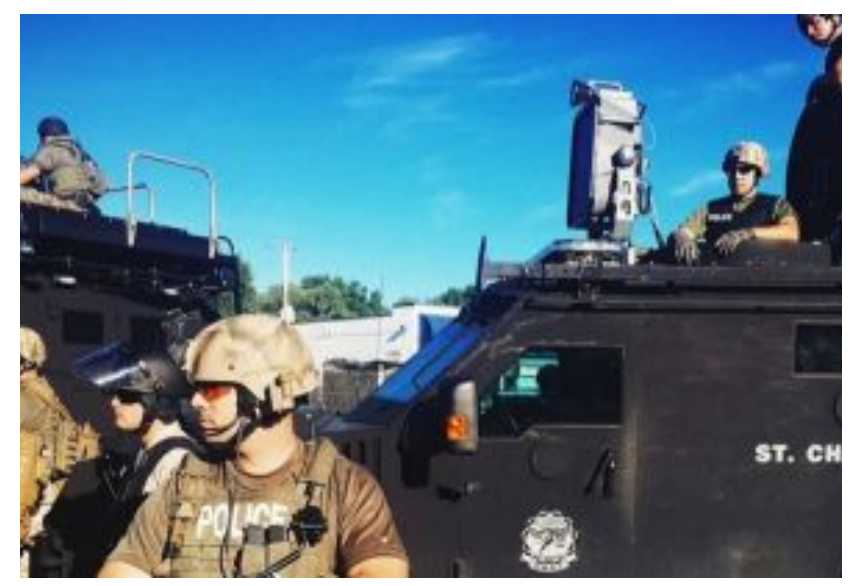

Figure 1: The LRAD Infra-Sound Cannon mounted to a vehicle
The LRAD infra-sound device has potentially long-term effects, including permanent hearing loss. Human discomfort starts when sound hits $120 \mathrm{~dB}$, well below the LRAD's threshold. Permanent hearing loss begins at $130 \mathrm{~dB}$, and if the device is turned up to 140 $\mathrm{dB}$, anyone within its path would not only suffer hearing loss, but also lose their balance, and be unable to move out of the path of the audio. (Baldwin, 2014).

LRAD systems are deployed at airports to sonically deter birds from residing in the pats of aircrafts. The bio-acoustic deterrent helps minimize bird strikes. It means that this device is available for military, police, secret services and also for agricultural companies to sonically deter birds, (reportedly: AT Dunaj Dubnik, Slovakia, their monitoring cars: TN 181 EB, NZ 708 FY, NZ 702 EG), etc.

From the above information it follows that the similar bioacoustic deterrents may have been developed also in other countries, first of all in other powers, such as Russia, China, India. Reportedly, above mentioned bio-acoustic deterrents may use also the Russianbased organized crime (RBOC), and also in different local groups of organized crime.

As it was published in Western media, Russian ambassadors keep dying in mysterious ways. For example, former Russian ambassador to the United Nations, Vitaly Churkin, who died in February 2017 in New York. The US State Department asked the New York medical examiner's office to not release his autopsy.

Reportedly, seven Russian ambassadors have died in mysterious ways over the last two years. What's concerning here is that Russia, according to Richard Walton, Scotland Yard's former counter-terror commander, is skilled it is disguising, probably by using biological or chemical agents that leave no trace. There are simply a lot of really weird coincidences in our world, Rolf Mowatt-Larsen, an intelligence expert at the Harvard Kennedy School, told media. (Brown, 2017).

I was working at the Embassy of the Slovak Republic to Russia in Moscow during the years 2002-2006 as the First Secretary and have also some similar problems with Sonic Attacks. In December, 2017 I have sent my request to the Ministry of Foreign Affairs of the Slovak Republic (MoFA SR) in Bratislava to make investigation of my case of sonic health problems. The officials of the MoFA SR have sent me than a letter rejecting my request for as minimum financial rehabilitation from suffered damage during my above diplomatic mission in abroad.

Recently I hope that the investigation of the Havana-Case in your State Department will prove my experiences. Especially, the AMA's journal JAMA is by my opinion not the best solution for a new types of Sonic Weapons mechanisms investigation. I am also publishing articles in U. S. scientific journals at the field of Biology during several years and I am convinced that the JAMA is too conservative, old-fashioned, out-dated scientific journal. They have only very limited information about new weapon technologies used recently by military and security forces of the modern states. From this reason I am rejecting the JAMA's conclusions in Havana-Case investigation as not enough qualified! (Skopec I., 2017).

Scientific solution for constant ringing in your ear: Apparently, around 2 million American's can't work because of tinnitus, and it's also the most common service-connected disability in veterans. The condition doesn't have a cure yet, but those suffering from it might not have to endure all the phantom ringing, clicking and hissing for life, thanks to a device developed by researchers from the University of Michigan. Their creation treats tinnitus by using precisely timed sounds 
and weak electrical pulses designed to persuade damaged nerves in the region of the brainstem called dorsal cochlear nucleus into working correctly again.

Team leader and U-M Medical School professor Susan Shore explained: When the main neurons in the dorsal cochlear nucleus, called fusiform cells, become hyperactive and synchronize with one another, the phantom signal is transmitted into other centers where perception occurs. If we can stop these signals, we can stop tinnitus.

The team tested the small, box-like device on guinea pigs first before testing it 20 minutes on patients. They found that the loudness of the phantom sounds decreased by 12 decibels - that's as loud as the hum of the light bulb - in some of the patients who received both sounds and electrical pulses. A couple of subjects even said their tinnitus disappeared completely. However, those who only received sounds didn't report change in their condition. (Skopec II., 2017).

Due to the way their device works, it can only treat somatic tinnitus. People who have this variant can modulate the phantom ringing/hissing they hear by pressing a part of their face and forehead or clenching their jaw. Studies say two-thirds of tinnitus patients suffer from somatic forms of the condition, making their device a promising treatment for most people. The researchers are trying to find a way to make it work just as well for non-somatic patients, too. They are also conducting more studies and tests to figure out how to make its effects last longer, since the testers' symptoms came back after a couple of weeks.

For people with tinnitus, the persistent sense of ringing in the ears is mildly annoying at best and disabling at worst. This new device may help ease the phantom noises. The experimental device uses precisely timed sound and skin stimulation to target nerve activity in the brain. Animal studies have identified specific nerve cells in the brain: fusiform cells, that signal phantom sounds to the rest of the brain.

S. Shore said that the research team is definitely encouraged by above results, but they need to optimize the length of treatments, identify which subgroups of patients may benefit most, and determine if this approach works in patients who have nonsomatic forms of the condition that that can't be modulated by head and neck maneuvers. (Reinberg, 2018, Moon, 2018) About solution for possible cancer's case see my new article titled: "De-Programming Colorectal Cancer by Increase in Cholesterol Level”. (Skopec IV., 2018).

\section{Conflicts of interests}

Author declares no conflict of interests.

\section{Acknowledgement}

The author gratefully acknowledge the assistance of Dr.Marta Ballova, Ing. Konrad Balla, Livuska Ballova, and Ing. Jozef Balla.

Copyright: $\odot 2018$ Skopec R. This is an open-access article distributed under the terms of the Creative Commons Attribution License, which permits unrestricted use, distribution, and reproduction in any medium, provided the original author and source are credited. 